\title{
Introduction to the special issue "The shadow economy, tax evasion and governance"
}

\author{
Aloys Prinz • Sascha Hokamp
}

Published online: 13 February 2015

(C) Springer-Verlag Berlin Heidelberg 2015

In an economically globalized world, new and hitherto hardly satisfactory mastered governance tasks arise, in particular for the taxation of companies and capital. The example of Greece, Italy, and Spain shows what kind of problems for public finance may occur when a significant proportion of economic activity takes place in the shadows, i.e., without paying duties and taxes. This will not only undermine tax morale in general, but also complicates the provision of public goods as, e.g., roads and bridges, or increases national debt. As the sovereign debt crisis in the euro zone demonstrated, a large shadow economy can have significant negative economic consequences for any member state in a currency union.

The shadow economy and tax evasion are at least partially caused by misguided tax policies, as well as by other weaknesses of local and federal governance. Without a deeper understanding of the shadow economy and tax evasion, as well as their relation to tax policy and state governance, an effective and efficient reduction of these side effects of government policy is nearly impossible.

To study determinants and consequences of the shadow economy and tax evasion, the biannual Münster shadow economy conferences have been established in 2009. The conferences are dedicated to the empirical, experimental, agent-based and theoretical analysis of all topics surrounding the shadow economy, tax evasion and tax compliance. The scientific disciplines involved cover economics, econophysics, and psychology, to name only a few. The participants come from a large number of countries, from South Korea to the United States and from Russia to South Africa.

\footnotetext{
A. Prinz $(\varangle)$

University of Münster, Münster, Germany e-mail: Aloys.Prinz@wiwi.uni-muenster.de

S. Hokamp

University of Hamburg, Hamburg, Germany

e-mail: Sascha.Hokamp@uni-hamburg.de
} 
In July 2013, the third conference on the shadow economy and tax evasion problems was held in Münster (Germany). At this meeting, a special focus was placed on issues of governance associated with economic underground activities and taxation.

A small number of contributions to this conference were selected through a peerreview process for publication in this Special Issue of Economics of Governance. The selection criteria were suitability of the content for this journal, as well as the quality of the papers. Finally, five papers were singled out via the peer review process. They are briefly described below.

As indicated above, research on the shadow economy and tax evasion is an interdisciplinary and multi-method endeavor. The first paper in this Special Issue is an empirical paper by Matti Viren ("Why so little revenues are obtained from a presumed large shadow economy?") on the size of the shadow economy in Finland and the revenues that may be generated from a more rigorous control of firms' tax compliance by tax authorities. The author employs a micro-dataset for Finland to analyze why enhanced inspections of firms do not result in large increases of revenues although Finland has a substantial shadow economy. Surprisingly, size, economic performance and firm ownership are among the main causes of the disappointing revenue increase. The paper is a valuable contribution to the understanding of the shadow economy as it demonstrates that bad firm governance in combination with a particular firm size and structure may prevail in the shadow economy. The crucial remaining question is whether better firm governance and performance might be used as a lever to restrain a country's shadow economy.

The paper of the psychologists Christoph Kogler, Stephan Muehlbacher and Erich Kirchler ("Testing the „slippery slope“ framework among self-employed taxpayers”) emphasizes two very different modes of tax compliance governance, called "trust" and "power", respectively. Persuading citizens to pay their taxes voluntarily by providing tax services and other collaborative measures on the side of tax authorities creates a different climate in tax affairs than applying strict audits, penalties and police measures to enforce tax compliance in a so-called "cops-and-robbers" climate. Although both modes may be equally successful in collecting taxes, the well-being of taxpayers and citizens can be very different. In a questionnaire study, the authors test their framework with self-employed taxpayers. The paper is a hint at the connection between governance modes of tax authorities and the resulting behavior of taxpayers. The approach is an important innovation, especially for economists who emphasized perhaps too one-sidedly - the "power" approach to enforce tax compliance.

Gareth D. Myles, Nigar Hashimzade, Frank Page and Matthew D. Rablen ("The use of agent-based modelling to investigate tax compliance") make use of two computational agent-based tax evasion models to investigate the behavior of taxpayers in combination with targeted audit strategies of tax authorities. In their first approach, they examine tax compliance and occupational choice with risky or non-risky individual income; in their second framework, they extend their approach by implementing social networks as well as individual attitudes and beliefs. Among other things, the authors find that the random auditing of taxpayers is not the best audit strategy in the sense of first-order stochastic dominance. The paper contributes essentially to the literature by demonstrating that agent-based modeling has the potential to capture sophisticated decision-making on tax compliance and tax evasion that is based on behavioral choice, 
complex optimization and learning due to the exchange of information within social networks.

The agent-based paper of Geoffrey Warner, Hettithanthringe S. Wijesinghe, Uma Marques, Osama Badar, Erik Hemberg, Jacob Rosen and Una-May O'Reilly ("Modeling tax evasion with genetic algorithms") applies elements of computer science, economics and theoretical biology to tax compliance. Constructs frequently used in biology, for instance grammatical evolution, chromosomes, genotypes and phenotypes, are employed to explore tax evasion schemes. Moreover, decision heuristics and fitness measures allow for examining audit strategies of tax authorities at the macro-level without any kind of optimization procedure at the micro-level. This interdisciplinary paper may enable policymakers to anticipate complex tax evasion schemes and to integrate them in their process of decision-making.

The last paper in this Special issue is the theoretical economics contribution of Juan Mendoza ("The protection of private property: The government as a free-rider"). His starting point is a quite simple question: Who protects private property in a country? In the spirit of Adam Smith, this question seems rather strange as one of the central arguments in favor of a tax-financed state is the governmentally enforced guarantee of private property by fighting and punishing theft. However, there are countries where private security forces are employed to protect private property. In a sense, the government in these states free-rides on private security forces that provide privately a public good. The crucial point in the author's analysis is the role the inefficiency of stealing, as well as taxation, plays for government behavior. The innovative element in his analysis is the interaction between private and public provision of the public good "security". Not only private persons react to government activities, but also the government responds in a certain way to the decision of private persons. The consequence is that not only individuals and private groups may free-ride on government activities, but also the government may exploit private activities with respect to public goods.

The selected papers in this Special Issue shed some light on the shadow economy, tax compliance and governance issues. However, the analysis of these areas is incomplete. One particular aspect is how money earned in cash in the shadow economy is smuggled back into the official economy and-with respect to tax evasion-how income is concealed from tax authorities. As demonstrated by a number of spectacular cases of tax fraud, financial institutions seem to be the intermediaries in these transactions. Therefore, the role of financial intermediaries will be in the focus of the next shadow economy conference, shadow 2015. 